\title{
The Seminal Vesicle as Source of Sex Attracting Substances in the African Catfish, Clarias gariepinus
}

\author{
J.W. RESINK, R. VAN DEN HURK*, R.F.O. GROENINX VAN ZOELEN and E.A. \\ HUISMAN $^{1}$ \\ Department of Experimental Zoology, Research Group for Comparative Endocrinology, \\ University of Utrecht, P.O. Box 80.058, 3508 TB Utrecht (The Netherlands) \\ ${ }^{1}$ Department of Fish Culture and Fisheries, Agricultural University, P.O. Box 338, $6700 \mathrm{AH}$ \\ Wageningen (The Netheriands)
}

(Accepted 8 December 1986)

\begin{abstract}
Resink, J.W., Van Den Hurk, R., Groeninx van Zoelen, R.F.O. and Huisman, E.A., 1987. The seminal vesicle as source of sex attracting substances in the African catfish, Clarias gariepinus. Aquaculture, 63: 115-127.
\end{abstract}

Attraction tests were performed with female African catfish placed in a U-shaped two-choice maze. A conspecific was placed in both ends of the aquarium behind a perforated partition. An unovulated female fish allowed to choose between water containing a male and water containing a female conspecific did not show an obvious preference. After hormonally induced ovulation, however, females spent more time at the side of the male fish. Such a preference was absent in ovulated anosmic females. When confronted with a male fish from which the seminal vesicle was extirpated and an intact male fish, female fish spent more time on the side of the latter after ovulation. Removal of the testes and a subsequent enlargement of the seminal vesicle made males more attractive for ovulated females. These results indicate that shortly after ovulation, female African catfish are attracted by male conspecifics, and that the male pheromone originates from the seminal vesicle. Subjection to an ovulated female appeared to induce a rise in circulating gonadotropin in both male and female catfish.

\section{INTRODUCTION}

Chemicals used for intraspecific communication have been called pheromones (Karlson and Lüsher, 1959). The majority of pheromones are recognized by olfaction; of these the best known are the sex attractants of insects (Atkins, 1980). Chemical communication is also important in fish (Liley, 1982; Liley and Stacey, 1983; Stacey et al., 1986). Reproductive organs, skin, mucus,

*To whom correspondence should be addressed. 
urophysis and urine are claimed to be sources of, or transporters of, pheromones. Gonadal steroid glucuronides appear to function as sex attractants and ovulation inducers in zebrafish, Brachydanio rerio (Van Den Hurk and Lambert, 1983; Lambert et al., 1986; Van Den Hurk et al., 1987). Likewise, Colombo et al. $(1980,1982)$ demonstrated that etiocholanolone glucuronide produced by the mesorchial gland of male black goby, Gorbius jozo, serves as an attractant for female conspecifics.

Steroid glucuronides are produced in postovulatory ovaries (Lambert and Van Den Hurk, 1982), in testis (Schoonen and Lambert, 1986a) and in the seminal vesicle of African catfish, Clarias gariepinus (Schoonen and Lambert, $1986 \mathrm{~b})$. These conjugates may be involved in reproduction, since the capacity to form them in feral African catfish is markedly enhanced during the breeding season, both in testes and in the seminal vesicle (Resink et al., 1987b); an additional increase is observed in the latter organ during actual spawning (Resink et al., 1987a). The latter phenomenon is accompanied by a rise of circulating gonadotropin.

In the present study we attempted to determine if ovulated and non-ovulated female African catfish show a preference for conspecifics of a particular sex, and whether this behaviour is due to pheromones perceived by olfaction. We also studied the pheromonal role of the testis and seminal vesicle separately in intersexual attraction and the possible influence of pheromones on plasma gonadotropin levels.

\section{MATERIAL AND METHODS}

\section{Animals}

Mature male and female African catfish, Clarias gariepinus, (1-2 years old, $300-600 \mathrm{~g}$ ) were used. They were raised in the laboratory under an annual photoperiod normal for the time of year in The Netherlands.

Fish were fed Trouvit trout pellets (Trouw, Putten, The Netherlands) at a rate of $2-3 \%$ of their body weight per day.

\section{Attraction tests}

Attraction tests were performed in a 200-I U-shaped glass maze consisting of a testing chamber and two end arm compartments (Fig. 1). The testing chamber was built up from two side compartments $(50 \times 100 \mathrm{~cm})$ and a connecting mid compartment $(25 \times 100 \mathrm{~cm})$. The side arms were each partitioned into two sections, the side compartment and the end arm compartment, by an opaque perforated partition (diameter of holes, $5 \mathrm{~mm}$ ) placed $45 \mathrm{~cm}$ from the rear wall. The bottom of the tanks was covered with $1 \mathrm{~cm}$ of gravel. Except for the front, all aquarium windows were painted black. Dechlorinated and cop- 


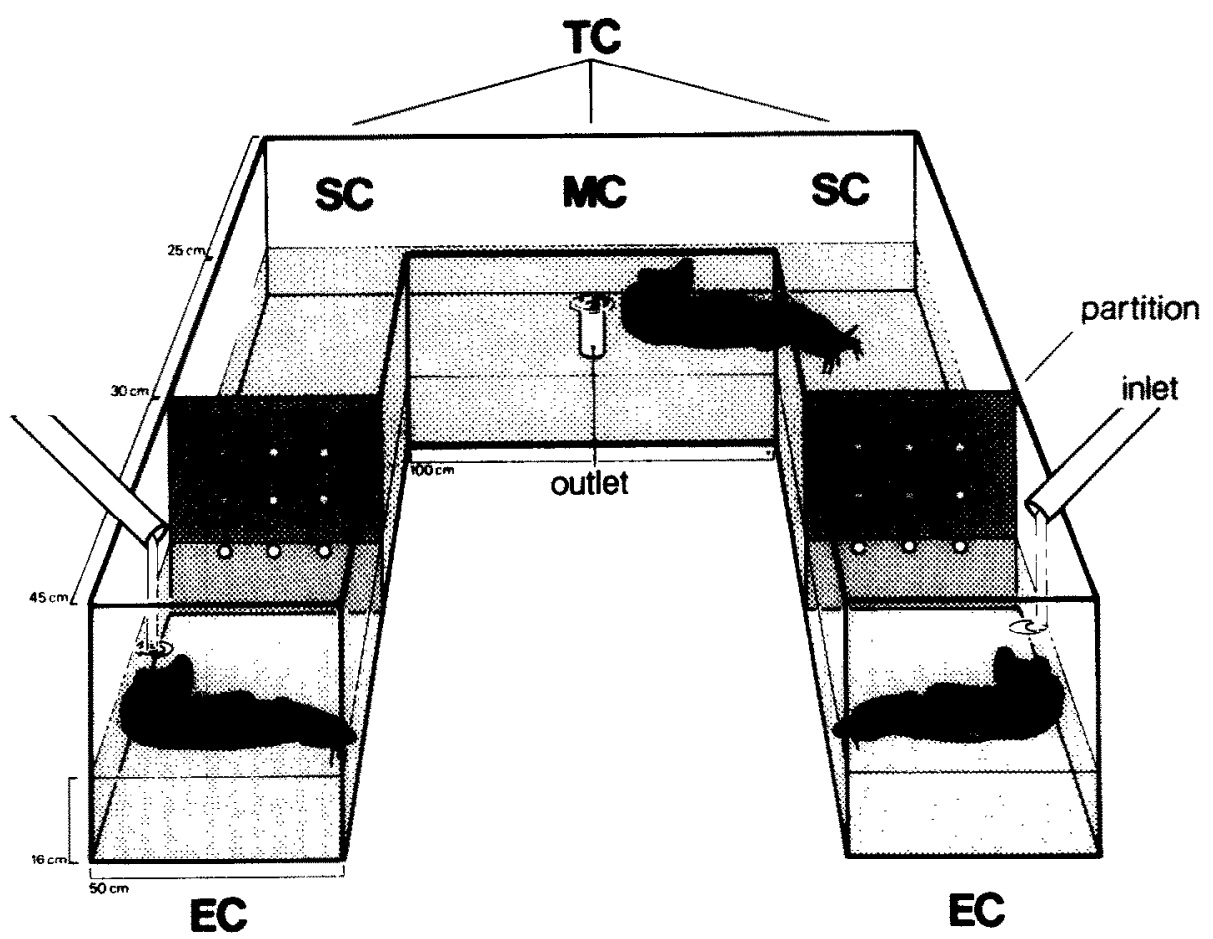

Fig. 1. Diagrammatic view of the U-shaped two-choice maze showing the testing chamber (TC), the end arm compartments (EC), the perforated partitions, water inlets and water outlet. The testing chamber is composed of a mid compartment (MC) and two side compartments (SC).

per-free tap water at $27^{\circ} \mathrm{C}$ was led into each side compartment at $0.25 \mathrm{l} / \mathrm{min}$; water flowed out through a central drain. The water level in each aquarium was $16 \mathrm{~cm}$.

Single female catfish were placed into the testing chamber. In addition, male or female catfish of equal size and age were placed into the end arm compartments as odor sources. Fish in the testing chamber were observed with video equipment, located in another room. Fish were pre-adapted to testing conditions by placing them in the test maze 2 days before each experiment. They were not fed during this period. Unovulated fish, placed in the testing chamber of the test system, were continuously observed for $60 \mathrm{~min}$ between 10.00 and $12.00 \mathrm{~h}$, and the time spent in the mid compartment and in each of the two side compartments was calculated. Ovulation in test females was induced by injecting at $17.00 \mathrm{~h}$ with $5 \mathrm{mg}$ pimozide (a gift from Jansen Pharmaceuticals Ltd, Beersum, Belgium) and $0.05 \mathrm{mg}$ LHRHa (Des-Gly ${ }^{10}$ [D-Ala ${ }^{6}$ LHRH ethylamide; a gift from Dr. J.Th. Gielen, Intervet International B.V., Boxmeer, The Netherlands) per $\mathrm{kg}$ bodyweight, suspended in a vehicle of $0.8 \% \mathrm{NaCl}$, $0.1 \%$ sodium metabisulphite and $0.25 \%$ bovine serum albumin (BSA, fraction 
V; Sigma), according to De Leeuw et al. (1985). Control fish were injected with an equivalent volume of the pimozide-LHRHa vehicle. Between 10.00 and $12.00 \mathrm{~h}$ on the next day, the time spent by the female in the different compartments of the testing chamber was again scored continuously for $60 \mathrm{~min}$. Tests in which fish remained motionless for more than 15 min during the observation period were excluded. All test aquaria were thoroughly rinsed with tapwater before each experiment.

Blood samples were taken from fish in the end arm compartments by puncturing the caudal vasculature using heparinized syringes, when they were placed in the test system and again at the end of an experiment, i.e. $20 \mathrm{~h}$ after injection of the female in the testing chamber. Blood samples were centrifuged (for 10 min at $800 \mathrm{~g}$ and $4^{\circ} \mathrm{C}$ ) and plasma stored at $-20^{\circ} \mathrm{C}$ until assayed.

\section{Experiment 1}

In the first series of attraction experiments females were allowed to choose between a male in one end arm compartment and a female in the other. Anosmic or sham-operated female catfish were tested. Females were made anosmic 4 days before the start of the experiment by anaesthetizing them with a $1 \%$ solution of 2-phenoxy-ethanol pipetted onto the gills, boring a hole $(4 \times 6 \mathrm{~mm})$ with a dental drill in the skull above the olfactory tracts, removing the fat and cranial fluid by gentle aspiration and sectioning both olfactory tracts. The hole in the skull was then filled up with molten cacao butter. Sham-operated female fish were exposed to similar surgical conditions, but the olfactory tracts were not sectioned. Sham-operated females were injected with pimozide-LHRHa $(n=9)$ or vehicle $(n=10)$; anosmic females received pimozide-LHRHa $(n=10)$. Ovulation was checked by the release of eggs from the ovipore following slight pressure on the abdomen.

\section{Experiment 2}

In the second series of experiments females $(n=10)$ were offered the choice between a male, whose seminal vesicle was surgically extirpated, in one end arm compartment and a sham-operated male in the other. In another set of experiments, females $(n=9)$ were subjected to a fish without testes and a shamoperated male in the opposite end arm compartment.

Testes and seminal vesicles were removed through a $4 \mathrm{~cm}$ incision in the abdomen of anaesthetized fish. The wound was sutured with silk (USP $3 / 0$, Serag Weissner). Sham-operated fish were exposed to similar surgical conditions, but their testes and seminal vesicles were not removed. Operated fish were permitted to recover for 2 weeks in separate aquaria. At the end of each experiment, gonadosomatic index (GSI) and seminal vesicle somatic index (SVSI) were determined, i.e. GSI $=$ (testes weight/body weight $) \times 100$; SVSI $=($ seminal vesicle weight $/$ body weight $) \times 100$. 


\section{GTH measurement}

The gonadotropin $(\mathrm{GTH})$ content in the blood plasma was measured using a homologous radioimmunoassay for catfish GTH according to the method of (Goos et al., 1986). The most important characteristics of this assay are its accuracy of $4-8 \%$ and its range of $0.4-6.3 \mathrm{ng} \mathrm{GTH} / \mathrm{ml}$ plasma for $100-\mu \mathrm{l}$ plasma samples.

\section{Statistical analysis}

The means of GTH, GSI, SVSI and the percentage time spent by the test female in the different compartments are given with the standard error of the mean (SEM). GTH, GSI and SVSI values of different groups of fish were compared with a Student's $t$-test. A paired $t$-test was used to compare GTH values and percentage time spent in a compartment before and after injection with pimozide-LHRHa or vehicle, and to compare percentage time spent in the different side compartments by the same fish (Sokal and Rohlf, 1969).

\section{RESULTS}

\section{Experiment 1}

Test females ovulated when injected with pimozide-LHRHa. These females spent significantly more time in the side compartment with the intact male fish (Fig. 2). This preference was absent before these females were injected with pimozide-LHRHa and when unovulated females, injected with vehicle, were tested. Ovulated female fish which were also rendered anosmic did not show a preference for the side compartment holding a male fish. When the perforated partition separating the male from the ovulated female fish was removed, ovulated females approached and butted the males repeatedly, which finally led to spawning acts as described by Bruton (1979) and Van Der Waal (1974). These spawning activities resulted in viable larvae.

Plasma GTH levels in male and in female fish that were stocked in the end arm compartments during this experiment are shown in Figs. 3 and 4 respectively. At the end of experiments, GTH values in these female fish were distinctly elevated as compared to those at the start of the experiments. In these females, the highest values were observed after hormonally induced ovulation of anosmic or sham-operated fish from the mid section. In males, GTH levels were slightly elevated after ovulation of the test females.

\section{Experiment 2}

When given the choice between a sham-operated and a seminal vesicle-extirpated male, ovulated females spent significantly more time on the side of the 

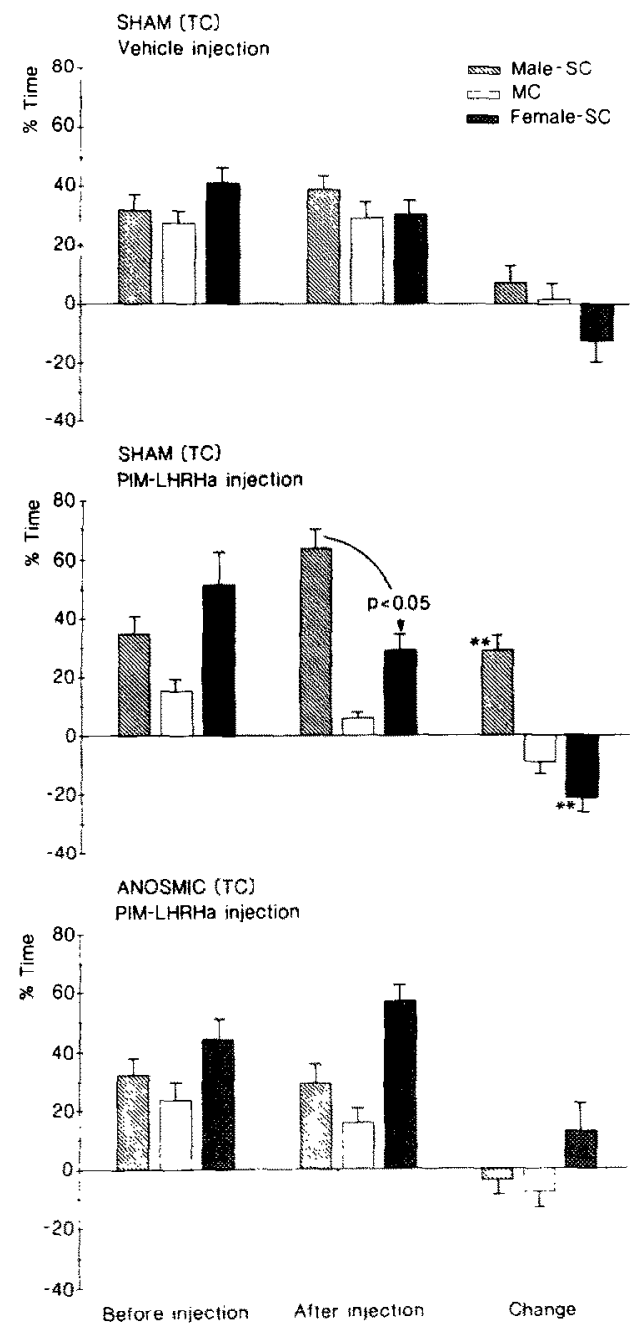

Fig. 2. Mean percentage time spent in the side compartment extending to the end arm compartment with a male (Male-SC), with a female (Female-SC) or the mid compartment (MC) by a sham-operated female (SHAM) injected with vehicle (no ovulation, $n=10$ ) or pimozide-LHRHa (ovulation, $n=9$ ), or an anosmic female (ANOSMIC) injected with pimozide-LHRHa (ovulation, $n=10$ ). The situations before and after injection, and the change due to injection of the female in the testing chamber (TC) are shown. Values are means \pm SEM. Significant difference, $P<0.05$; significant increase/ decrease, ${ }^{* *} P<0.01$.

maze holding the intact male compared with the situation before ovulation (Fig. 5). Unovulated females, however, spent significantly more time near the end arm compartment holding a male without seminal vesicle. Plasma GTH levels in seminal vesicle-extirpated males did not change during these experiments; sham-operated males, however, showed significantly increased GTH 

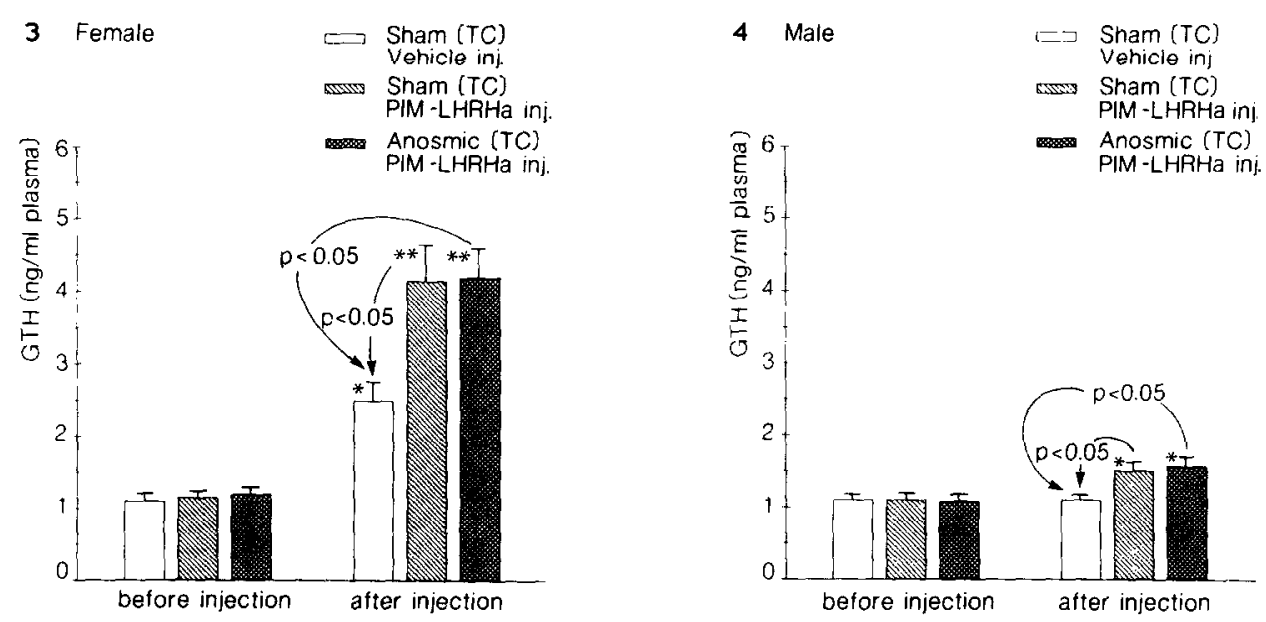

Fig. 3.Mean plasma GTH levels in female catfish stocked in the end arm compartments, before and after injection of sham-operated (Sham) females from the testing chamber (TC) with vehicle (no ovulation, $n=10$ ) or pimozide-LHRHa (ovulation, $n=9$ ), or anosmic (Anosmic) females injected with pimozide-LHRHa (ovulation, $n=10$ ). Values are means \pm SEM. Significant difference, $P<0.05$; significant increase/decrease, ${ }^{*} P<0.05,{ }^{* *} P<0.01$.

Fig. 4. Mean plasma GTH levels in male catfish stocked in the end arm compartments (EC), before and after injection of sham-operated (Sham) females from the testing chamber (TC) with vehicle ( $n$ ovulation, $n=10$ ) or pimozide-I.HRHa (ovulation, $n=9$ ), or anosmic (Anosmic) females injected with pimozide-LHRHa (ovulation, $n=10$ ). Values are means $\pm S E M$. Significant difference, $P<0.05$; significant increase/decrease, ${ }^{*} P<0.05$.
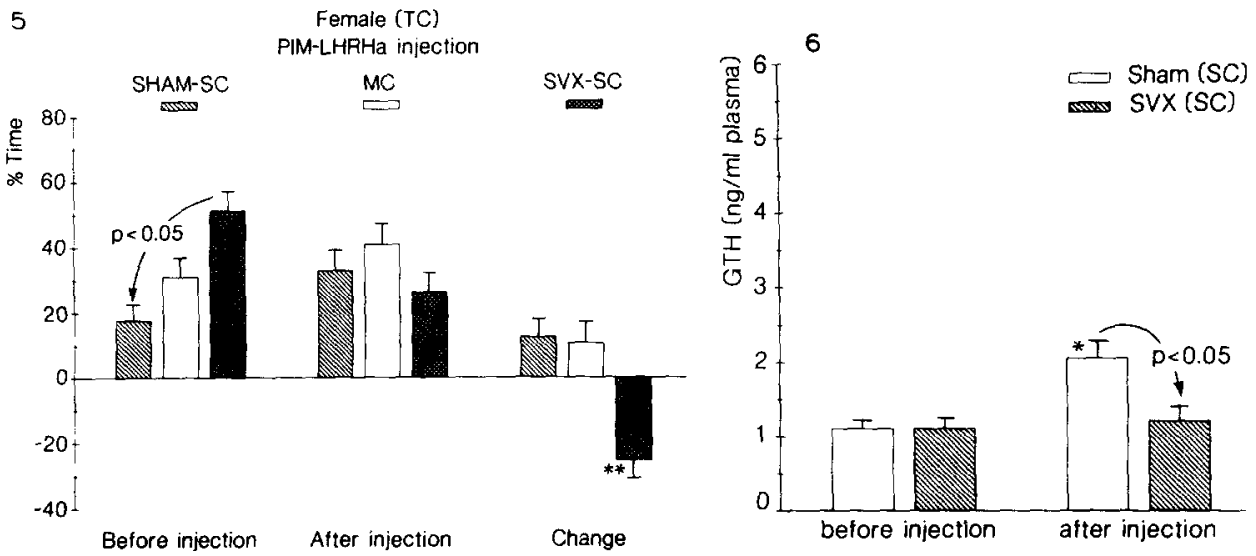

Fig. 5. Mean percentage time spent by females $(n=10)$ in the side compartment extending to the end compartment with a sham-operated male (SHAM-SC), with a seminal vesicle-extirpated male (SVX-SC) or the mid compartment (MC). The situations before and after and the change due to injection of the female in the testing chamber (TC) with vehicle (no ovulation) or pimozide-LHRHa (ovulation) are shown. Values are means \pm SEM. Significant difference, $P<0.05$, significant increase/decrease, ${ }^{* *} P<0.01$.

Fig. 6. Mean plasma GTH levels in sham-operated (Sham, $n=10$ ) and seminal vesicle-extirpated (SVX, $n=10$ ) males stocked in the end arm compartments, before and after injection of a female in the testing chamber with pimozide-LHRHa. Values are means \pm SEM. Significant difference, $P<0.05$; significant increase/decrease, ${ }^{*} P<0.05$. 


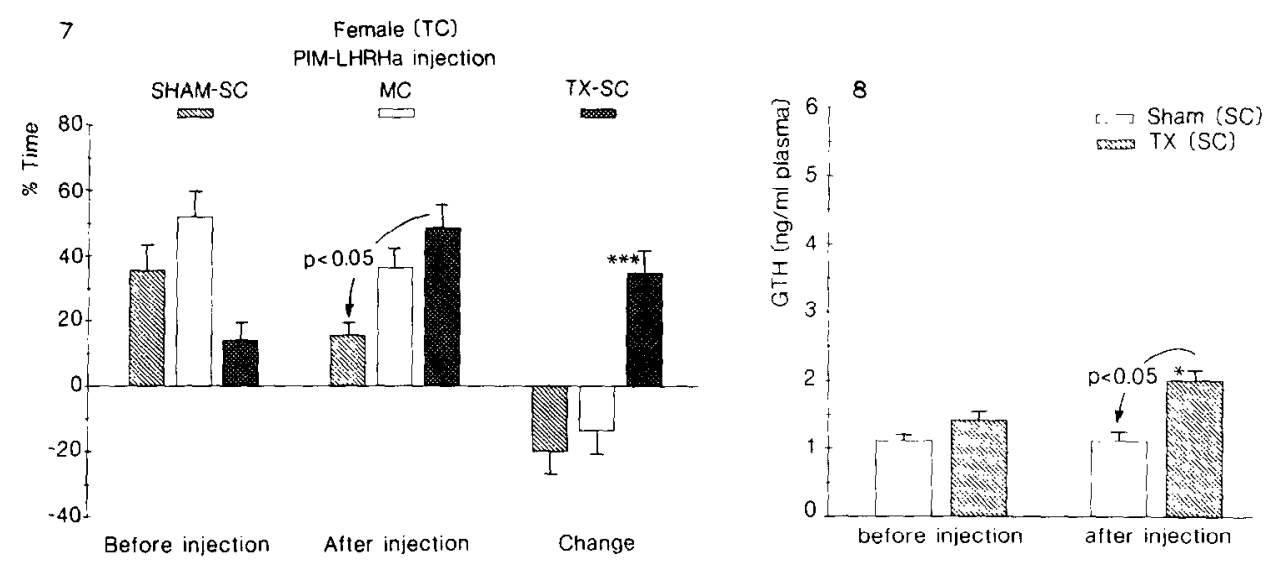

Fig. 7. As Fig. 5, but with a testes-extirpated male $(n=9)$ instead of a seminal vesicle-extirpated male in one of the end arm compartments. TX-SC: side compartment extending to the end arm compartment with a testes-extirpated male. Significant increase/decrease ${ }^{* * *} P<0.005$.

Fig. 8. As Fig. 6, but with testes-extirpated males (TX, $n=9$ ) instead of seminal vesicle-extirpated fish.
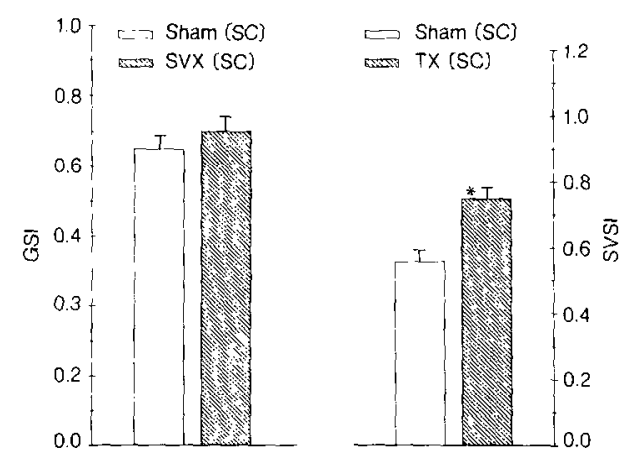

Fig. 9. Mean gonadosomatic index (GSI) in sham-operated (Sham, $n=10$ ) and seminal vesicleextirpated (SVX, $n=10$ ) males; mean seminal vesicle somatic index (SVSI) in sham-operated (Sham, $n=9$ ) and testes-extirpated (TX, $n=9$ ) males. Values are means \pm SEM. Data of males were compared with those of sham-operated males. ${ }^{*} P<0.05$.

values (Fig. 6). GSI values of seminal vesicle-extirpated males were not significantly different (Fig. 9) when compared to sham-operated males.

When subjected to a castrated male and a sham-operated male, ovulated females spent more time in the compartment at the side of the male without testes (Fig. 7). In these experiments, GTH levels in sham-operated fish did not change (Fig. 8), but those of castrated fish had increased. At the end of the experiments, 2 weeks after the operation, castrated fish showed elevated SVSI values (Fig. 9). 


\section{DISCUSSION}

Unovulated female Clarias gariepinus did not show a significant preference for the odor of either a male or a female; neither did they show a significant preference when subjected to males without testes and intact males. Unovulated females, however, appear strongly attracted to seminal vesicle-extirpated fish. Seminal vesicles in males thus seem to secrete an odor that makes them less attractive for unovulated females. In the catfish, Ictalurus melas, seminal vesicle extracts appeared to be involved in both avoidance and attraction responses (Rubec and Thomas, 1979). In addition, extracts of skin and urine evoked similar responses in this species. Rubec (1979) attempted to fractionate and identify the active constituent in the urine of Ictalurus melas and concluded that at least two pheromones are present, one lipid and the other proteinaceous. Changes in the proportion of the two pheromones in the urine appear to depend on the physiological state of the donor.

Ovulated females are attracted to males. This intersexual attraction response appears to be due to chemical signals, since anosmic ovulated females did not show a preference for males. Similar observations have also been reported for other teleosts. Ictalurus species recognize sex odor (Todd et al., 1967; Kendle, 1970; Richards, 1974). Attractiveness of males for females has also been found in Salmo gairdneri (Newcombe and Hartman, 1973), Blennius pavo (Laumen et al., 1974), several Belontiid species (Lee and Ingersoll, 1979), Petromyzon marinus (Teeter, 1980) and Gobius jozo (Colombo et al., 1980, 1982). Perception of pheromones by olfaction was demonstrated in Bathygobius soporator (Tavolga, 1976), Carassius auratus (Partridge et al., 1976), Plecoglossus altivelis (Honda, 1979) and Brachydanio rerio (Van Den Hurk and Lambert, 1983). These chemical messengers may either be steroid hormones (Johansen, 1985; Stacey and Sorensen, 1987) or conjugated steroids, like steroid glucuronides (Colombo et al., 1980, 1982; Van Den Hurk and Lambert, 1983; Lambert et al., 1986; Van Den Hurk et al., 1987). In Clarias gariepinus, the seminal vesicle is an important source of steroid glucuronides (Schoonen and Lambert, 1986b).

These data show that the seminal vesicle in African catfish emits sex attractants, since ovulated females prefer intact male fish to seminal vesicle-extirpated males, and castrated fish having enlarged seminal vesicles to intact males. Seminal vesicles were previously indicated as pheromone producers in Ictalurus melas (Rubec and Thomas, 1979). In male Gobius jozo (Colombo et al., 1980 ), the mesorchial gland has a similar function. Furthermore, testes, milt, anal fin appendages, skin, mucus and urine were shown to contain sex pheromones in several male teleost species (for reviews, see Colombo et al., 1982; Liley, 1982; Liley and Stacey, 1983; Stacey et al., 1986).

Stimulation of male pheromone production after treatment with gonadotropin was demonstrated in Blennius pavo (Laumen et al., 1974). Enlargement of the seminal vesicle after castration in the catfish Heteropneustes fossilis 
(Sundararaj and Nayyar, 1969) led the authors to suggest that this castration effect might be due to stimulation by gonadotropin. Castration in Clarias garipienus indeed results in a rise of circulating $\mathrm{GTH}$, which is followed by a decline within 2 weeks of surgery (De Leeuw et al., 1986). GrTH values of castrated catfish in the present study were not elevated 2 weeks following surgery.

Attraction of an ovulated female to a male is followed by a series of spawning activities when the partition between them is removed. Sex attractants in Clarias gariepinus are thus probably essential for successful spawning. An ovulated catfish showed her attention for the male by repeatedly approaching and butting him. This stimulates the male to chase the female, finally leading to oviposition. The attraction of ovulated female African catfish to male conspecifics was not seen previously (Van Der Waal, 1974; Bruton, 1979). In Clarias batrachus, however, similar approaching actions were observed (Thakur, 1976).

One can only speculate about the physiological regulation of female interest in males and reproductive behaviour. In female guppies, blood estrogen levels are considered to stimulate their reproductive behaviour (Liley, 1972). In goldfish, prostaglandins produced in the postovulatory ovary stimulate reproductive behaviour, the responsiveness for these compounds probably being influenced by gonadotropic and steroid hormones (Liley and Stacey, 1983). In feral African catfish, ovulation is accompanied by a strong gonadotropin output (Resink et al., 1987a) and conspicuous changes in ovarian steroidogenesis (Lambert and Van Den Hurk, 1982; Schoonen et al., 1987). Endogenous hormonal changes in fish thus may regulate a female's interest in males and the following reproductive behaviour. On the other hand, postovulatory ovaries are frequently considered as sources of pheromones (for reviews, see Colombo et al., 1982; Liley and Stacey, 1983; Stacey et al., 1986). Several reports referred to the steroid glucuronide nature of such ovarian pheromones (Van Den Hurk and Lambert, 1983). In African catfish, Lambert and Van Den Hurk (1982) showed that testosterone glucuronide could only be synthesized in postovulatory ovaries. Keeping these data in mind, it may not be overlooked that postovulatory pheromones of female Clarias gariepinus may influence the sexual behaviour of the fish either directly or indirectly via a stimulation of male pheromone production.

At the end of attraction tests with unovulated catfish in the testing chamber confronted with a male and another female in the end arm compartments, plasma GTH values were slightly increased in the latter females. Apparently, the stay in the test system itself stimulates plasma GTH levels in female fish. This may be due to favourable environmental conditions, such as low stocking density, low water level, gravel bottom and high water temperature. An additional stimulation of GTH output in female fish from end arm compartiments took place when the female in the testing chamber had ovulated. Furthermore, unlike unattractive males, attractive males also showed enhanced GTH levels after a confrontation with ovulated females. The rise in plasma GTH content 
in both male and female catfish from the end arm compartments after ovulation of a female in the testing chamber might be due to postovulatory pheromones produced by the latter fish. Gonadotropin release stimulated by pheromones is well known in higher vertebrates (Bronson, 1971; Maruniak and Bronson, 1976; Kamel et al., 1977; Maruniak et al., 1978; Aron, 1979; Harding, 1981). Recently, Kobayashi et al. (1986) demonstrated that pheromones from ovulated goldfish evoke a GTH surge in male conspecifics.

\section{ACKNOWLEDGEMENTS}

The authors wish to thank Prof. Dr. P.G.W.J. Van Oordt, Prof. Dr. M.P. Schreibman and Dr. P.W. Sorensen for critically reviewing the manuscript, Ms. M. van Hattum and Ms. R. van Gelderen for typing the manuscript and the Image Processing and Design Department of the Subfaculty of Biology for making the drawings.

These investigations were supported by the Netherlands Foundation for Technical Research (STW), future Technical Science Branch/Division of the Netherlands Organization for the Advancement of Pure Research (ZWO).

\section{REFERENCES}

Aron, C., 1979. Mechanisms of control of the reproductive function by olfactory stimuli in female mammals. Physiol. Rev., 59: 229-284.

Atkins, M.D., 1980. Introduction to Insect Behaviour. Mcmillan, New York, NY, 237 pp.

Bronson, F.H., 1971. Rodent pheromones. Biol. Reprod., 4: 344-357.

Bruton, M.N., 1979. The breeding biology and early development of Clarias gariepinus (Pisces: Claridae) in Lake Sibaya, South Africa, with a review of breeding in species of the subgenus Clarias (Clarias). Trans. Zool. Soc. London, 35: 1-45.

Colombo, L., Marconato, A., Colombo Belvédère, P. and Friso, C., 1980. Endocrinology of teleost reproduction: a testicular steroid pheromone in the black goby, Gobius jozo L. Boll. Zool., 47: 355-364.

Colombo, L., Colombo Belvédère, P., Marconato, A. and Bentivegna, F., 1982. Pheromones in teleost fish. In: C.J.J. Richter and H.J.Th. Goos (Editors), Proc. Int. Symp. Reproductive Physiology of Fish, Wageningen, The Netherlands, 26 August 1982. PUDOC, Wageningen, pp. 84-94.

De Leeuw, R., Resink, J.W., Rooyakkers, E.J.M. and Goos, H.J.Th., 1985. Pimozide modulates the luteinizing hormone-releasing hormone effect on gonadotropin release in the African catfish, Clarias lazera. Gen. Comp. Endocrinol., 58: 120-127.

De Leeuw, R., Wurth, Y.A., Zandbergen, M.A., Peute, J. and Goos, H.J.Th., 1986. The effect of aromatizable androgens, non-aromatizable androgens, and estrogens on gonadotropin release in castrated African catfish, Clarias gariepinus (Burchell). A physiological and ultrastructural study. Cell Tissue Res., 243: 487-594.

Goos, H.J.Th., De Leeuw, R., Burzawa-Gérard, E., Richter, C.J.J. and Terlou, M., 1986. Purification of gonadotropic hormone from the pituitary of the African catfish, Clarias gariepinus (Burchell), and the development of a homologous radioimmunoassay. Gen. Comp. Endocrinol., 62: 162-170. 
Harding, C.F., 1981. Social modulation of circulating hormone levels in the male. Amer. Zool., 21: 223-231.

Honda, H., 1979. Female sex pheromone of the ayu, Plecoglossus altivelis, involved in courtship behaviour. Bull. Jpn. Soc. Sci. Fish., 45: 1375-1380.

Johansen, P.H., 1985. Female pheromone and the behaviour of male guppies (Poecilia reticula) in a temperature gradient. Can. J. Zool., 63: 1211-1213.

Kamel, F., Wright, W.W., Mock, E.J. and Frankel, A.I., 1977. The influence of mating and related stimuli on plasma levels of luteinizing hormone, follicle stimulating hormone, prolactin, and testosterone in the male rat. Endocrinology, 101: 421-429.

Karlson, P. and Lüsher, M., 1959. Pheromones: a new term for a class of biologically active substances. Nature (London), 183: 55-56.

Kendle, E.R., 1970. Sexual discrimination by olfaction in the black bulhead, Ictalurus melas. State of Nebraska Game and Parks Commission Job Progress Reports, March 1, 1969-February 28, 1970, pp. 21-31.

Kobayashi, M., Aida, K. and Hanyu, I., 1986. Pheromone from ovulatory female goldfish induces gonadotropin surge in males. Gen. Comp. Endocrinol., 63: 451-455.

Lambert, J.G.D. and Van Den Hurk, R., 1982. Steroidogenesis in the ovaries of the African catfish, Clarias lazera, before and after an HCG-induced ovulation. In: C.J.J. Richter and H.J.Th. Goos (Editors), Proc. Int. Symp. Reproductive Physiology of Fish, Wageningen, The Netherlands, 2-6 August 1982. PUDOC, Wageningen, pp. 99-102.

Lambert, J.G.D., Van Den Hurk, R. Schoonen, W.G.E.J., Resink, J.W. and Van Oordt, P.G.W.J., 1986. Gonadal steroidogenesis and the possible role of steroid glucuronides as sex pheromones in two species of teleosts. Fish Physiol. Biochem., 2 (1-4): 101-107.

Laumen, J., Pern, U. and Blum, V., 1974. Investigations on the function and hormonal regulation of the anal appendices in Blennius pavo (Risso). J. Exp. Zool., 190: 47-56.

Lee, C.T. and Ingersoll, D.W., 1979. Social chemosignals in five Belontiidae (Pisces) species. J. Comp. Physiol. Psychol., 93: 117-118.

Liley, N.R., 1972. The effect of estrogens and other steroids on the sexual behavior of the female guppy, Poecilia reticulata. Gen. Comp. Endocrinol. Suppl., 3: 542-552.

Liley, N.R., 1982. Chemical communication in fish. Can. J. Fish. Aquat. Sci., 39: 22-35.

Liley, N.R. and Stacey, N.E., 1983. Hormones, pheromones and reproductive behavior. In: W.S. Hoar, D.J. Randall and E.M. Donaldson (Editors), Fish Physiology, Vol. IX, Reproduction. Academic Press, New York and London, pp. 1-63.

Maruniak, J.A. and Bronson, F.H., 1976. Gonadotropic resonses of male mice to female urine. Endocrinology, 99: 963-969.

Maruniak, J.A., Coquelin, A. and Bronson, F.H., 1978. The release of LH in male mice in response to female urinary odors: characteristics of the response of young males. Biol. Reprod., 18: 251-255.

Newcombe, C. and Hartman, G., 1973. Some chemical signals in the spawning behavior of rainbow trout (Salmo gairdneri). J. Fish. Res. Board Can., 30: 995-997.

Partridge, B.L., Liley, N.R. and Stacey, N.E., 1976. The role of pheromones in the sexual behaviour of the goldfish. Anim. Behav., 24: 291-299.

Resink, J.W., Van Den Hurk, R., Voorthuis, P.K., Terlou, M. and Viveen, W.J.A.R., 1987a. Quantitative enzyme histochemistry of steroid and glucuronide synthesis in testes and seminal vesicle, and its correlation to plasma gonadotropin level in Clarias gariepinus. Aaquaculture, 63: 97-114.

Resink, J.W., Schoonen, W.G.E.J., Van Den Hurk, R., Viveen, W.J.A.R. and Lambert, J.G.D., $1987 \mathrm{~b}$. Seasonal changes in steroid metabolism in the male reproductive organ-system of the African catfish, Clarias gariepinus. Aquaculture, 63: 59-76.

Richards, I.S., 1974. Caudal neurosecretory system: possible role in pheromone production. J. Exp. Zool., 187: 405-408. 
Rubec, P.J., 1979. Effect of pheromones on behavior of ictalurid catfish. Ph.D. Thesis, Texas A \& M University, College Station, TX, 165 pp.

Rubec, P.J., and Thomas, P., 1979. Anatomical and concentration effects of pheromones on ictalurid catfish. Am. Zool., 19: 967.

Schoonen, W.G.E.J. and Lambert, J.G.D., 1986a. Steroid metabolism in the testis of the African catfish, Clarias gariepinus (Burchell), during the spawning season, under natural conditions and kept in ponds. Gen. Comp. Endocrinol., 61: 40-52.

Schoonen, W.G.E.J. and Lambert, J.G.D., 1986b. Steroid metabolism in the seminal vesicle of the African catfish, Clarias gariepinus (Burchell), during the spawning season, under natural conditions and kept in ponds. Gen. Comp. Endocrinol., 61: 355-367.

Schoonen, W.G.E.J., Schoonen, W.G.E.J., Granneman, J.C.M., Lambert, J.G.D. and Van Oordt, P.G.W.J., 1987. Steroidogenesis in the testes and seminal vesicles of spawning and non-spawning African cattish, Clarias gariepinus. Aquaculture, 63: 77-88.

Sokal, R.R. and Rohlf, F.J., 1969. Biometry. The Principles and Practice of Statistics in Biological Research. Freeman, San Francisco, CA, 776 pp.

Stacey, N.E. and Sorensen, P.F., 1987. 17 $\alpha, 20 \beta$-dihydroxy-4-pregnen-3-one: a steroidal primer pheromone increasing milt volume in the goldfish, Carassius auratus. Can. J. Zool., 64: 2412-2417.

Stacey, N.E., Kyle, A.L. and Liley, N.R., 1986. Fish Reproductive Pheromones. In: D. Duvall, D. Muller-Schwarze and R.M. Silverstein (Editors), Chemical Signals in Vertebrates, Vol. IV, Fourth International Conference on Chemical Signals in Vertebrates, Laramie, WY, 27-30 July 1985. Plenum, New York, NY, in press.

Sundararaj, B.I. and Nayyar, S.K., 1969. Effects of castration and/or hypophysectomy on the seminal vesicles of the catfish, Heteropneustes fossilis (Bloch). J. Exp. Zool., 172: 369-384.

Tavolga, W.N., 1976. Chemical stimuli in reproductive behaviour in fish communication. Experientia, 32: 1093-1095.

Teeter, J,, 1980. Pheromone communication in sea lampreys (Petromyzon marinus): implications for population management. Can. J. Fish. Aquat. Sci., 37: 2123-2132.

Thakur, N.K., 1976. On the spawning behavior of Clarias batrachus. Jpn. J. Ichthyol., 23: 178-180.

Todd, J.H., Atema, J. and Bardach, J.E., 1967. Chemical communication in social behavior of a fish, the yellow bullhead (Ictalurus natalis). Science, 158: 672-673.

Van Den Hurk, R. and Lambert, J.G.D., 1983. Ovarian steroid glucuronides function as sex pheromones for male zebrafish, Brachydanio rerio, Can. J. Zool., 61: 2381-2387.

Van Den Hurk, R., Van Zoelen, G.A., Schoonen, W., Resink, J.W. and Lambert, J.G.D., 1987. Do testicular steroid conjugates of zebrafish, Brachydanio rerio, evoke ovulation in female conspecifics? Gen. Comp. Endocrinol., 66: 18-19.

Van Der Waal, B.C.W., 1974. Observations on the breeding habits of Clarias gariepinus (Burchell). J. Fish Biol., 6: 23-27. 